\title{
BLINDNESS! A TERRIBLE AFTERMATH OF DENTAL TREATMENT
}

\author{
Vandana Chhabra ${ }^{1}$, Ajay Chhabra ${ }^{2}$ \\ ${ }^{1}$ Reader, Dept. of Oral and Maxillofacial Surgery, SKSS Dental College \& Hospital, Ludhiana \\ ${ }^{2}$ Professor and Head, Dept. of Conservative Dentistry and Endodontics, Bhojia Dental College and Hospital, Baddi, Himachal Pradesh.
}

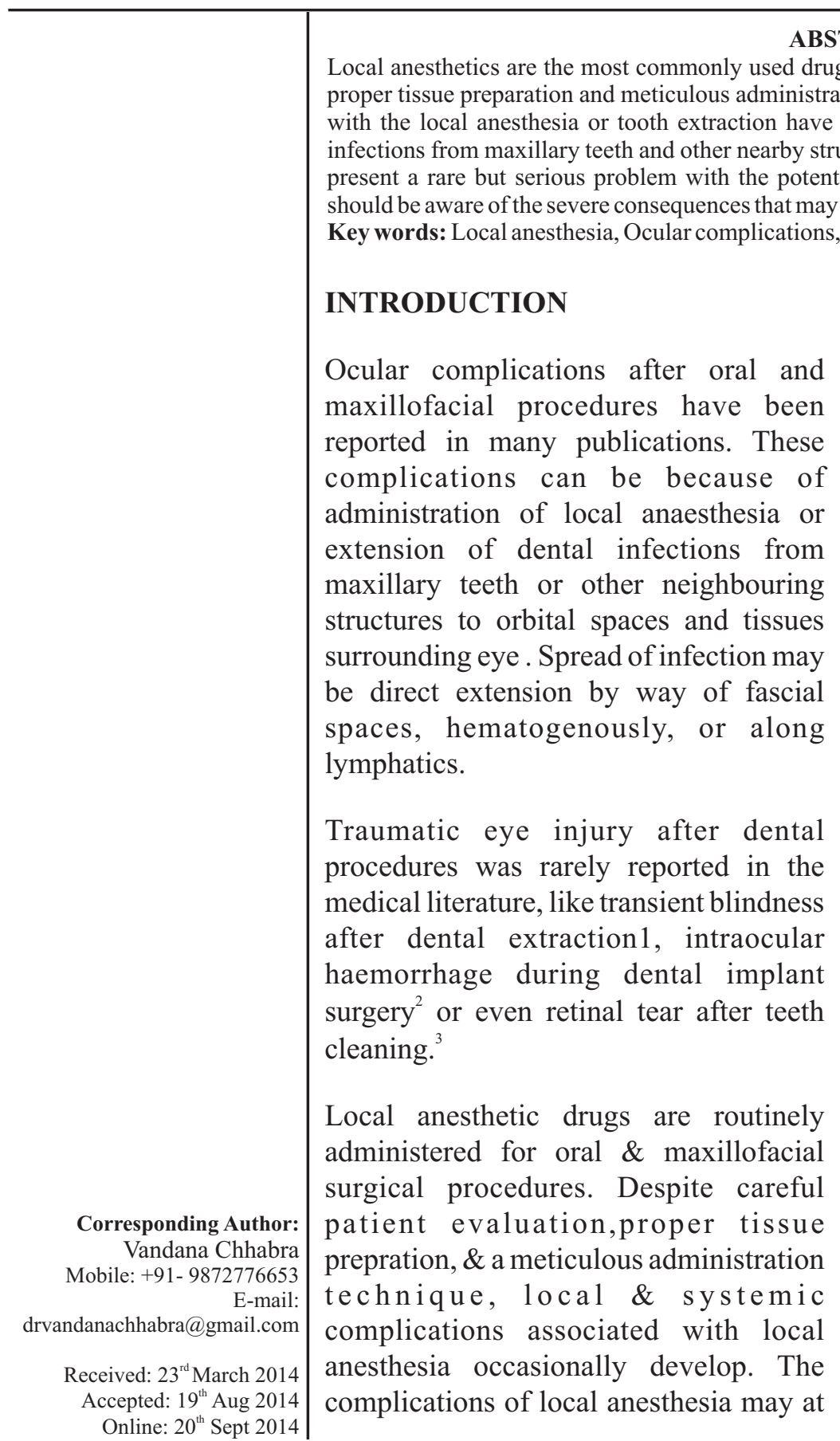

times involve structures further from oral cavity, including middle ear4 and eye. ${ }^{5}$ Patients have experienced visual or motor problems, either from post. Sup. Alveolar injection or an inf. Alveolar injection. Visual problems include blurring of vision, ${ }^{6,7}$ amaurosis or blindness (temporary or permanent). ${ }^{8-11}$ Motor problems include mydriasis, palpebral ptosis and diplopia. Horner-like manifestations involving ptosis, enophthalmos and miosis of the eye have also been reported.

\section{DISCUSSION}

There is little doubt that local anesthesias used in dentistry are safe agents. Complications associated with LA can be divided into systemic and regional, as also those determined by the local anesthetic agents used and the technique of administration. Some of the systemic reactions include vasovagal syncope, anaphylactic shock, toxicity, tissue necrosis, and facial nerve palsy; and the ophthalmic complications include temporary blindness, diplopia, temporary paralysis of cranial nerves III, IV, and VI, oculomotor muscle paralysis, mydriasis, palpebral ptosis, and even permanent blindness. 
Wei Cheong Ngeow et $\mathrm{al}^{12}$ reported 2 cases of transient loss of power of accommodation in 1 eye following inferior alveolar nerve block. Both the patients were given inferior alveolar nerve blocks. The first patient recovered after 15 minutes and the affect in the second patient lasted for 10 minutes.

Fortunately, most complications in the eye have been transient. For example, Rood8 in 1972 reported a case in which $1.5 \mathrm{~mL}$ of lidocaine with epinephrine $(1: 80,000)$ was injected into an inferior alveolar nerve. Immediate loss of vision developed in the ipsilateral eye, along with upper-eyelid ptosis and medial strabismus, which resulted in double vision. The patient also developed ischemia of the palatal mucosa. However, within 5-45 minutes, all symptoms had disappeared. Unfortunately, cases of permanent complications have also been reported..$^{9-11}$

Among complications involving the orbit, the most notable are temporary paralysis of the cranial nerves that govern eye movement: the oculomotor (CN III), trochlear (CN IV) and abducens (CN VI) nerves. ${ }^{8,13-17}$

According to Pickering18 the loss of power of accommodation is a consequence of the paralysis of the ciliary muscle either due to injury or anesthesia of $\mathrm{CN}$ III. When complete, paralysis of CN III results in ptosis, external strabismus, dilatation of the pupil and loss of power of accommodation as the sphincter pupillae, the ciliary muscle and the internal rectus are paralyzed. Occasionally paralysis may affect only a part of the nerve. Thus, there may be internal strabismus from spasm of the internal rectus; accommodation for near objects only from spasm of the ciliary muscle; or miosis (contraction of the pupil) from irritation of the sphincter of the pupil. ${ }^{18}$

Blaxter and Britten ${ }^{19}$ reported several cases involving transient amaurosis and diplopia, and postulated that an intra-arterial injection of the inferior alveolar artery had occurred, with the anesthetic agent travelling to the internal maxillary artery, the middle meningeal artery and, finally, the lacrimal and ophthalmic arteries.

Goldenberg ${ }^{14,15}$ reported a similar case following a mandibular injection, and traced the anesthetic to the lacrimal artery. Rood $^{8}$ also described a possible arterial route for diffusion of a vasoconstrictive agent from the alveolar artery to the internal maxillary and middle meningeal arteries and, finally, from the lacrimal to the ophthalmic artery by way of anastomotic connections. The maxillary artery has been shown to have a highly variable relation to the branches of the mandibular neurovascular bundle ${ }^{20}$ and enormous individual variation in its topography, diameter, size of the downward loop and its position relative to the mandibular foramen. ${ }^{21}$ The middle meningeal artery can arise as the second major branch of the maxillary artery. ${ }^{20}$ Moreover, in 4\% of patients, the ophthalmic artery arises not from the internal carotid but from the middle meningeal artery following direct flow from the external carotid artery. ${ }^{22}$ These variations have been postulated to contribute to ocular complications following intraoral local anesthetic injections. Other authors have proposed the existence of vascular malformations or anomalies that may produce the retrograde anesthetic diffusion phenomenon. ${ }^{23,24}$

Data obtained by contrast radiography and hemodynamic and electroencephalographic studies in rhesus monkeys indicated that carotid blood flow is reversible. ${ }^{25}$ Results showed that even small amounts of local anesthetic agents, when injected inadvertently into a branch of the external carotid artery, may enter the cerebral circulation, most likely through retrograde flow into the common and then internal carotid arteries. Thus, another possible mechanism to explain the loss of power of accommodation is the retrograde flow of local anesthetic agent to the cavernous sinus area. As any cerebral disease causing pressure on the cavernous sinus will result in paralysis of the $\mathrm{CN}$ III $^{18}$ due to their close proximity the same way, rather than cerebral disease, the cause of paralysis of the nerve concerned could be deposition of local anesthetic via retrograde flow.

Transient diplopia in dental outpatient clinic has been reported by SM Balaji ${ }^{25}$ where a healthy 32 -year-old female patient felt double vision after few minutes of posterior superior alveolar block anesthesia. The condition was subsequently diagnosed as transient diplopia due to temporary paralysis of lateral rectus muscle due to involvement of the VI cranial nerve. The patient recovered in 30 minutes and the treatment was performed successfully.

Maxillary local anesthetic injections, particularly those deposited near the pterygoid canal are known to cause diplopia of the ipsilateral eye and are estimated to occur 
in about $35.6 \%$ of cases. This often results from the local anesthesia diffusing superiorly and medially to anesthetize the orbital nerves. There are no known reports in the literature of permanent diplopia. ${ }^{26}$ The hypothesis for ophthalmological manifestation of an inferior alveolar nerve block has been proposed as local anesthetic solution reaches the orbit through vascular, neurological and lymphatic network. ${ }^{27}$ They proceed to describe that oculomotor disturbances after injection of dental local anesthetics is that of inadvertent deposition of some of the drug into the inferior alveolar artery, mandibular canal or PSA artery. By reverse flow, the anesthetic agent then reaches the internal maxillary and middle meningeal arteries, the orbital branch of the latter anastomosing with the lacrimal branch of the opthalmic artery. ${ }^{28}$

A patient whose abducent nerve is involved may complain of double vision and may exhibit limitation of abduction of the ipsilateral eye as well as paresthesia of the lateral side of the upper and lower eyelids in limited cases including the present case.
Several explanations have been put forward to explain the phenomenon. ${ }^{29}$

Alexander Kiderman and Jawad A. A. Tair ${ }^{30}$ in their article An eye for a tooth proposed a possible link between dental extraction and intra-ocular complications. They reported a case of 49 -year-old healthy female who underwent surgical extraction of root canal treated second right upper molar tooth. One day after the procedure the patient felt a strange sensation of blurred vision and threads in the right eye and later a white curtain covering the same. Retinal tears and viterous haemmorhage in the right eye were diagnosed and appropriately treated with laser. One week later, the vision was completely restored. According to the author Mental stress during the treatment and local epinephrine could cause blood pressure elevation. However, this is no more than an unproven theoretical explanation.

The more serious candidate to be the casual factor for the mentioned vitreous and retinal damages after tooth extraction is Valsalva manoeuvre ${ }^{31,32}$ The first

Table 1: Compares all the above mentioned possible ways by which this uncommon transient abducent nerve palsy secondary to a local anesthetic injection could be caused.

\begin{tabular}{|c|c|c|c|}
\hline Pathways & Ways & Present case & References \\
\hline $\begin{array}{l}\text { Vascular } \\
\text { Intra-arterial injection }\end{array}$ & $\begin{array}{l}\text { Inadverent penetration of the } \\
\text { needle Into artery or solution } \\
\text { diffusing into an artery }\end{array}$ & $\begin{array}{l}\text { Not possible-aspiration } \\
\text { was negative and because } \\
\text { arterial transportation } \\
\text { would cause widespread } \\
\text { effects }\end{array}$ & $\begin{array}{l}\text { Walker et al. (2004), } \\
\text { Malamed et al. (1997), } \\
\text { Crean et al. (1999), } \\
\text { Koumoura et al. (2001), } \\
\text { Goldenberg (1990) }\end{array}$ \\
\hline Intravenous injection & $\begin{array}{l}\text { Via the cavernous sinus and } \\
\text { pterygoid plexus }\end{array}$ & Possible in this case & $\begin{array}{l}\text { Walker et al. (2004), } \\
\text { Crean et al. (1999), } \\
\text { Koumoura et al. (2001), }\end{array}$ \\
\hline $\begin{array}{l}\text { Needle size } \\
\text { Size of needle }\end{array}$ & $\begin{array}{l}\text { 25-Gauge needle or above has the } \\
\text { potential to involve } \\
\text { pterygoid plexus if placed } \\
\text { incorrectly }\end{array}$ & $\begin{array}{l}\text { A24-gauge needle was } \\
\text { used }\end{array}$ & Freuen el al. (2007) \\
\hline $\begin{array}{l}\text { Bone pathways Unique } \\
\text { infraorbital Fissure and/or } \\
\text { unique Pterygopalatine fossa }\end{array}$ & $\begin{array}{l}\text { Anatomic variations possibly } \\
\text { aggravated by recumbent position }\end{array}$ & $\begin{array}{l}\text { Possible in the present } \\
\text { case }\end{array}$ & $\begin{array}{l}\text { Van der Bijl and Meyer } \\
\text { (1998), Sved et al. (1992) }\end{array}$ \\
\hline $\begin{array}{l}\text { Autonomic nervous system } \\
\text { stimulation of autonomic } \\
\text { nervous system by local } \\
\text { anesthetic solution }\end{array}$ & $\begin{array}{l}\text { Local anesthetic solution } \\
\text { stimulates the autonomic nervous } \\
\text { system }\end{array}$ & $\begin{array}{l}\text { Not possible as other signs } \\
\text { and features are not } \\
\text { consistent }\end{array}$ & $\operatorname{Kim}(2001)$ \\
\hline $\begin{array}{l}\text { Response to local anesthetic } \\
\text { solution Response to lignocaine } \\
\text { Solution }\end{array}$ & $\begin{array}{l}\text { Articaine has demonstrated } \\
\text { such ophthalmological } \\
\text { complication }\end{array}$ & $\begin{array}{l}\text { Lignocaine was used in } \\
\text { the present case }\end{array}$ & $\begin{array}{l}\text { Penarrocha-Diago et al. } \\
(2000)\end{array}$ \\
\hline
\end{tabular}


description of Valsalva haemorrhagic retinopathy was published in $1972^{32}$. During sudden strain from any reason, there is increase in intrathoracic pressure against a closed glottis decreasing venous return to the right heart. Following Valsalva manoeuvre, an abrupt rise in intraocular venous pressure causes retinal capillaries to rupture, and less commonly, vitreous haemorrhage.

Patients with a history of blood dyscrasias, diabetes mellitus, sickle cell anaemia and hypertension as well as those with a history of ocular venous occlusions have an increased risk for Valsalva retinopathy.

M. Peñarrocha-Diago ${ }^{33}$, presented a series of 14 cases of ophthalmologic complications after intraoral anesthesia of the posterior superior alveolar nerve. The most commonly encountered symptoms were diplopia, mydriasis, palpebral ptosis, and abduction difficulties of the affected eye. In all cases, these effects occurred a few minutes after injection of the anesthetic, followed by complete resolution without sequelae on cessation of the anesthetic effect. The pathogenic mechanism underlying suchophthalmologic disorders is discussed in terms of a possible diffusion of the anesthetic solution toward the orbital region.

Three of their cases developed Horner syndrome-like manifestations after anesthesia, all with ptosis, enophthalmos, and miosis. The diagnosis was based on the clinical picture. This complication is most likely caused by sympathetic block at the ciliary ganglion once the latter is reached by the anesthetic solution. It is illogical for block of the stellate ganglion to be responsible, as referred by Campbell et $\mathrm{al}^{34}$ because it is considerably more distant, and block at this level induces a much broader range of symptoms not seen in these particular cases. ${ }^{35}$

In 1972, $\operatorname{Rood}^{8}$ described a possible arterial route for diffusion of the vasoconstrictive agent from the alveolar artery to the internal maxillary and middle meningeal arteries, and finally from the lacrimal to the ophthalmic artery by way of anastomotic connections. In this way, the arteries nurturing the extrinsic and intrinsic muscles of the eye would develop vasoconstriction.

Table 2. Clinical characteristics of the 14 patients with ophthalmologic complications after dental anesthesia

\begin{tabular}{|c|c|c|c|c|}
\hline Case & Age (Y) & Sex & Alteration & $\begin{array}{r}\text { Duration } \\
\text { (Min) }\end{array}$ \\
\hline 1 & 65 & Woman & Palpebral ptosis, enophthalmos, miosis & 50 \\
\hline 2 & 29 & Woman & Palpebral ptosis, enophthalmos, miosis & 20 \\
\hline 3 & 53 & Man & Palpebral ptosis, enophthalmos, miosis & 40 \\
\hline 4 & 49 & Woman & External rectus muscle, mydriasis, ptosis (iii pair) & 45 \\
\hline 5 & 60 & Woman & External rectus muscle, mydriasis, ptosis (iii pair) & 30 \\
\hline 6 & 25 & Woman & External rectus muscle, mydriasis, ptosis (iii pair) & 60 \\
\hline 7 & 24 & Woman & Superior oblique muscle (iv pair) & 30 \\
\hline 8 & 32 & Woman & External rectus muscle (vi pair) & 45 \\
\hline 9 & 22 & Woman & External rectus muscle (vi pair), mydriasis & 60 \\
\hline 10 & 35 & Man & External rectus muscle (vi pair) & 90 \\
\hline 11 & 40 & Woman & External rectus muscle (vi pair), palpebral ptosis & 120 \\
\hline 12 & 73 & Woman & External rectus muscle (vi pair) & 130 \\
\hline 13 & 65 & Woman & External rectus muscle (vi pair) & 50 \\
\hline 14 & 40 & Woman & External rectus muscle (vi pair) & 30 \\
\hline
\end{tabular}


Table 3. Cases of ophthalmologic disorders after intraoral anesthesia reported in the literature

\begin{tabular}{|c|c|c|c|c|c|c|c|}
\hline Author & Year & Case & Technique & Age (Y) & Main alteration & Duration & Sequelae \\
\hline Cooper $^{23}$ & 1962 & 1 & IDNB & 46 & Ptosis, miosis diplopia & $5 \mathrm{~h}$ & No \\
\hline Blaxter et $\mathrm{al}^{24}$ & 1967 & 2 & IDNB & 16 & Diplopia, no abduction & $30 \mathrm{~min}$ & No \\
\hline Blaxter et $\mathrm{al}^{24}$ & 1967 & 3 & IDNB & 39 & Diplopia, mydriasis & $5 \mathrm{~h}$ & No \\
\hline Blaxter et $\mathrm{al}^{24}$ & 1067 & 4 & IDNB & 30 & Diplopia & $20 \mathrm{~min}$ & No \\
\hline Halesl $^{25}$ & 1970 & 5 & PSA & 16 & Mydriasis & $96 \mathrm{~h}$ & No \\
\hline $\operatorname{Rood}^{14}$ & 1972 & 6 & IDNB & 24 & Diplopia, ptosis, vertigo & $45 \mathrm{~min}$ & No \\
\hline Hyams $^{6}$ & 1976 & 7 & $\overline{P S A}$ & 34 & $\begin{array}{l}\text { Diplopia, ptosis, } \\
\text { mydriasis, no abduction }\end{array}$ & $2 \mathrm{w}$ & Ptosis for 4 months \\
\hline Campbell et al ${ }^{11}$ & 1979 & 8 & IDNB & 34 & Horner's syndrome & $2 \mathrm{~h}$ & No \\
\hline Petrelli et $\mathrm{al}^{4}$ & 1980 & 9 & MSA & 42 & Diplopia, no abduction & $90 \mathrm{~min}$ & No \\
\hline Norris $^{26}$ & 1982 & 10 & PSA & 17 & Diplopia, periocular pain & $9 \min$ & No \\
\hline Goldenberg $^{3}$ & 1983 & 11 & IDNB & 58 & Diplopia, no abduction & $20 \mathrm{~min}$ & No \\
\hline $\mathrm{O}^{\prime}$ Connor et $\mathrm{al}^{27}$ & 1983 & 12 & IDNB & 61 & $\begin{array}{l}\text { Diplopia, mydriasis, no } \\
\text { abduction }\end{array}$ & $30 \mathrm{~d}$ & No \\
\hline Kronman et al ${ }^{1}$ & 1984 & 13 & PSA & 37 & Diplopia & $50 \mathrm{~min}$ & No \\
\hline Goldenberg $^{2}$ & 1990 & 14 & $\overline{\text { PSA }}$ & 31 & Diplopia, no abduction & $3 \mathrm{~h}$ & No \\
\hline Madrid et $\mathrm{al}^{12}$ & 1990 & 15 & IDNB & 34 & $\begin{array}{l}\text { Vertigo, diplopia, } \\
\text { nystagmus }\end{array}$ & $3 \mathrm{~min}$ & No \\
\hline Marinho $^{5}$ & 1995 & 16 & IDNB & 25 & Diplopia, no abduction & $3 \mathrm{~h}$ & No \\
\hline Bandres et al ${ }^{9}$ & 1997 & 17 & PSA & 25 & $\begin{array}{l}\text { Diplopia, mydriasis, no } \\
\text { abduction }\end{array}$ & $50 \mathrm{~min}$ & No \\
\hline
\end{tabular}

IDNB, Inferior dental nerve block; PSA, posterior superior alveolar; MSA, middle superior alveolar

According to Kronman and $\mathrm{Kabani}^{36}$, perivascular trauma resulting from intraarterial injection or perforation of the vascular wall would stimulate the sympathetic fibers running alongside the internal maxillary artery until reaching the orbit. In this context, a series of symptoms (eg. vasoconstriction and mydriasis) would arise as a consequence of the increased sympathetic activity. This would explain the ocular muscle ischemia and mydriasis often observed in such cases. The local diffusion theory could be a further explanation, involving diffusion of the anesthetic solution through the vascular, lymphatic, and nervous networks communicating the pterigomaxillary fossa and the orbit.

Petrelli et a $\mathrm{l}^{37}$ considered that a defect in the bony cavity of the maxillary sinus could facilitate diffusion. Some authors advocate a venous diffusion phenomenon, ${ }^{38}$ communicating the pterigoid venous plexus and the ophthalmic vein through the orbital fissure. ${ }^{22}$ According to Goldenberg, ${ }^{15}$ a local anesthetic could pass through the cavernous sinus toward the ophthalmic vein, ultimately reaching the ophthalmic artery by way of a series of anastomoses. The 3 oculomotor nerves (III, IV, and VI) are closely related to the cavernous sinus and traverse the latter adhered to its lateral wall; in the opinion of Madrid et al, diffusion of anesthetic within the cavity would thus have a direct anesthetic effect on these nerves.

According to the M. Penarrocha ${ }^{33}$ the ophthalmologic disorders after intraoral anesthesia were caused by the direct diffusion of the anesthetic solution from the pterigomaxillary fossa, through the sphenomaxillary cavity, to the orbit. This would affect the ciliary ganglion, located between the optic nerve and the external rectus muscle of the eye. This ganglion receives parasympathetic fibers, originating in the accessory oculomotor nucleus, that accompany the common oculomotor nerve. The fibers form synapses in the ganglion and then produce 8 or 9 short ciliary nerves that end in the eye. Sympathetic fibers from the carotid plexus also traverse the ciliary ganglion (though without forming synapses at this point) and are incorporated to the short ciliary nerves before reaching the eye. ${ }^{39-41}$ In this way, the different manifestations observed may be explained in terms of either sympathetic or parasympathetic involvement, 
and the proximity of the external rectus muscle to the sphenomaxillary space is likely the reason why this muscle is more frequently affected. Based on this, if the anesthetic solution reaches the orbit, it could act by blocking the vegetative nervous system (sympathetic or parasympathetic) and produce vasoconstriction, myotoxicity, or could have direct effects on the nerve endings.

Kelly R. Magliocca ${ }^{42}$, reported a case of Transient diplopia following maxillary local anesthetic injection and extraction of a maxillary left second molar. Several vascular and bony anatomical pathways have been proposed to explain its occurrence based on the underlying regional anatomy, the sites of injection, and the pathways of spread of the anesthetic agent. ${ }^{15,43}$

\section{Vascular pathways}

Intra-arterial injection and intravenous absorption are 2 possible means of vascular transport of anesthetic into the orbital region. ${ }^{43}$ Both scenarios posit that a needle is over-inserted postero-medially at the maxillary tuberosity to enter the infratemporal fossa. ${ }^{44}$ The intraarterial pathway is described as inadvertent needle puncture of the maxillary artery, ${ }^{29}$ followed by spread of anesthetic agent into several successive arterial branches (middle meningeal artery, then via a common anastomotic branch into the orbit to the lacrimal branch of the ophthalmic artery). ${ }^{15,43}$

The venous pathway into the cavernous sinus is the most commonly cited explanation for postinjection abducens palsy ${ }^{29,43}$ The pterygoid venous plexus is found within the infratemporal fossa, and any anesthetic agent reaching this location would be in close contact with numerous small, thin-walled veins. ${ }^{15,44}$ Absorption would seem relatively easy, and transport into the cavernous sinus could occur via small emissary veins passing through foramen ovale to directly enter the cavernous sinus (Figure 1). Here, the abducens nerve is in close contact with the venous blood and vulnerable to the effects of any anesthetic agent present.

\section{Bony pathways}

Several bony anatomical features are often cited as responsible for allowing unintended spread of anesthetic agent and resultant abducens nerve palsy.

Two points regarding local anatomy are very important.

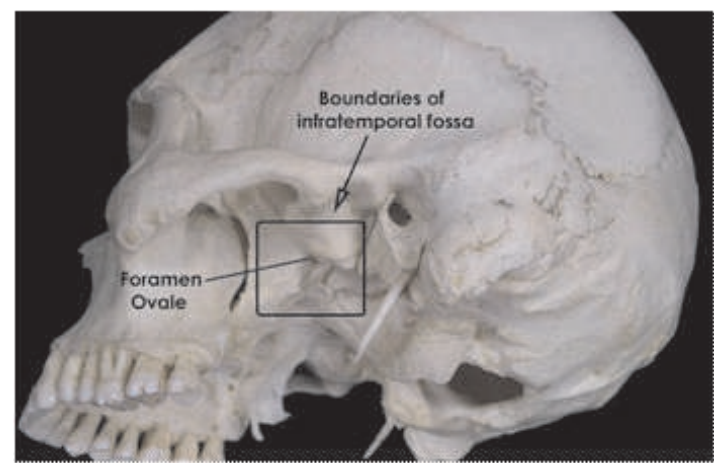

Figure 1. Rectangle approximates the extent of the infratemporal fossa, where the pterygoid venous plexus would be found. Foramen ovale contains small emissary veins that drain into the cavernous sinus. Cavernous sinus is located in the middle cranial fosssa and surrounds the abducens nerve at that location.

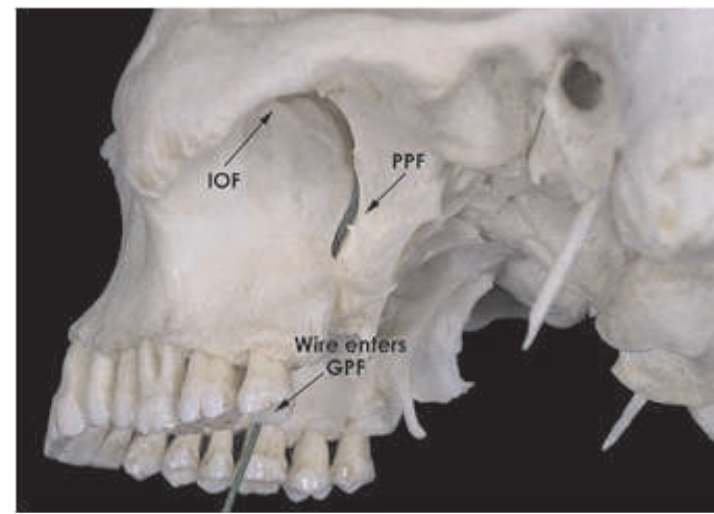

Figure 2. Local anesthetic injected posterior to the maxillary tuberosity or into greater palatine foramen may reach the orbital apex (not in view) by entering the pterygopalatine fossa. Green wire shows straight-line path from greater palatine foramen (GPF) to pterygopalatine fossa (PPF), and its continuation with the inferior orbital fissure (IOF).

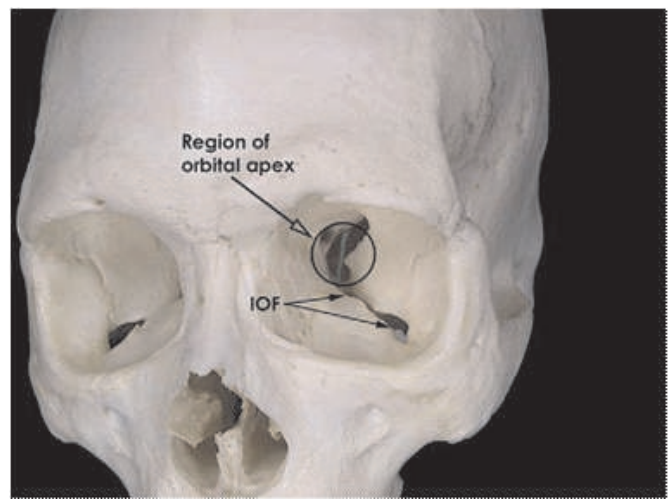

Figure 3. Anterior view of left orbit, showing the orbital apex and its relationship to the inferior orbital fissure (IOF). The green marker indicates continuity from the pterygopalatine fossa to the orbital apex, where the abducens nerve normally lies on the deep (intraconal) surface of the lateral rectus muscle but is not yet embedded within the muscle. 
1 The inferior orbital fissure and pterygopalatine fossa are in open communication with one another in the orbital region, and the greater palatine canal is in communication with the inferior aspect of the pterygopalatine fossa. Thus, anesthetic solution may diffuse widely among these bony openings, perhaps very easily in some individuals with a unique anatomic variation. The recumbent position of the patient during anesthetic administration may also have a role. ${ }^{43}$

2 The abducens nerve is most vulnerable in the region of the orbital apex, where it lies on the deep (intraconal) surface of the lateral rectus muscle. Anterior to this region, the nerve quickly enters the muscle, which is covered by dense fascia. Investigators have described anesthetic delivery near enough to the pterygopalatine fossa via the PSA injection, allowing for diffusion into the region of the orbital apex or inferior orbital fissure. ${ }^{15,43}$ Since the greater palatine canal is on a straight-line trajectory with the pterygopalatine fossa and orbital apex, injections at this location could introduce anesthetic into the orbital apex and induce a paresis of the abducens nerve by direct contact of the solution with the nerve at its most vulnerable location (Figure 2 and Figure 3 ).

Sved et al. ${ }^{45}$ documented the complications resulting from a technique designed to accomplish maxillary nerve anesthesia by advancing the needle into the greater palatine canal to a target depth of approximately $39 \mathrm{~mm}$. Notably, the 2 most common adverse effects observed in association with this technique were diplopia and orbital muscle paresis (most commonly involving the lateral rectus muscle). In 2 cases, the bony greater palatine canal was constricted, which limited needle penetration to $3 \mathrm{~mm}$ and $6 \mathrm{~mm}$, respectively. Maxillary anesthesia was still achieved in these cases, despite failure to reach the target depth. The authors did not state whether these 2 cases of a "constricted" canal resulted in diplopia or lateral rectus palsy. In the present case there was no intention or evidence of needle over-insertion during the palatal injection.

John Crean and Alison Powis ${ }^{29}$ have also explained neurological complications of local anesthetic as follows:

1 The inadvertent deposition of local anesthetic solution passes through the inferior orbital fissure to cause direct anesthesia of the abducent nerve.

2 The local anesthetic solution reaches the inferior ophthalmic vein via the pterygoid plexus or its communicating branches. This vein contains no valves and connects directly with the extrinsic muscles of the eye via the infraorbital foramen. An intraluminal injection may easily reverse the flow within the vessel, thus predisposing the muscles to the effect of the anesthetic solution.

3 Deposition of the anesthetic solution within the PSA artery causes a back flow into the connecting maxillary arery and subsequently into the middle menengial artery. There exists a constant anastomosis between the orbital branch of the middle menengial and the recurrent menengial division of the lacrimal branch of the ophthalmic artery. This lacrimal artery supplies the lateral rectus muscle, the lacrimal gland, and the outer half of the eyelids, which due to these anatomical considerations may explain these symptoms.

4 The local anesthetic solution reaches the abducent nerve within the cavernous sinus through the infratemporal fossa and the pterygoid plexus and its connecting emissary veins passing through the foramen ovale and lacerum. Different manifestations observed following the administration of local anesthetic agents may be explained in terms of either sympathetic or parasympathetic involvement.

Chun Kei-Lee ${ }^{46}$, while describing ocular complications after LA, explains that the local anesthetic solution reaches the orbit through a vascular, neurological, and lymphatic network that is responsible for ocular complications. Even while administering the inferior alveolar nerve block, ocular complications do occur. The author has suggested that the different clinical manifestations are due to different degrees of vascular anomaly.

Suresh Subramaniam ${ }^{47}$ reported a case of Orbital apex syndrome after tooth extraction in an immunocompromised patient. A 60 year-old man presented left upper gum swelling associated with left side facial pain for one-week duration. He was diagnosed to have generalised chronic periodontitis by dentist and underwent left 1 st upper molar tooth extraction after completion of one-week course antibiotic. After tooth extraction, he developed sudden onset left upper lid ptosis associated proptosis, which progressively increased in 5 hours duration. It was associated with left eye pain together with facial pain and deterioration of his left vision. Patient was not known to have diabetes mellitus or other medical illness. He was diagnosed to have left OAS due to left 
orbital abscess secondary to paranasal sinusitis following tooth extraction. At the same time his blood sugar level was very high at presentation and he was treated as newly diagnosed diabetes mellitus.

Extracting an infected tooth can gives a free access to the microorganisms to extend their vicinity to the nearby paranasal sinuses. Mostly infection to the ethmoidal sinus can lead to the incidence of OAS, even it is a rare situation but there were cases reported before. ${ }^{48}$ Eighty percent of reported cases with orbital infections were developed as a complication of infection of the paranasal sinuses, with ethmoidal sinusitis being the most common source. ${ }^{49,50}$ This is because the thin wall between orbit and ethmoidal air sinuses, where any infections can easily penetrate to orbital cavity. Most of the reported OAS cases occurred after few days following tooth extraction. ${ }^{48,51,52}$ This is mainly due to time taken for the infection to spread from infected tooth socket to maxillary sinus, then other paranasal sinuses and finally to orbital cavity. ${ }^{53}$ However, in our patient it occurred very fast within 5 hours. As we know orbit is a closed box area with lack of lymphatic and the valveless venous system ${ }^{50}$ and an underlying diabetes mellitus that was undiagnosed before could be a possible reason for the shorter incubation period. ${ }^{54}$

Nicholas Zachariades, et $\mathrm{al}^{48}$ reported a case of Orbital abscess that caused Visual loss following extraction of a tooth. Extension of dental infections from the maxillary teeth or other nearby structures to the orbital spaces and tissues surrounding the eye presents a rare but serious problem with the potential for causing significant impairment. ${ }^{55-57}$ Spread of infection and severity of sequelae depend on several factors including virulence of the microorganisms, the resistance of the patient, and the anatomy of the infected area. ${ }^{58}$ Spread of infection may be by direct extension by way of the fascial spaces, hematogenously (by infected thrombi through the venous system), or along lymphatic channels (although the existence of the latter in the area has been disputed). ${ }^{55}$ The spread of infection to the orbit is further facilitated by the loosely attached periorbita within the orbit, which are readily displaced by pus allowing entry into the orbit from the surrounding areas. ${ }^{59}$ It is the relation of the root apices to the adjacent muscles that most often determines the direction of spread, which follows the path of least resistance. ${ }^{60}$ The buccal cortical plate is very thin; thus, most abscesses penetrate buccally. ${ }^{5}$ Infection from the maxillary premolar and molar teeth may then perforate the maxillary buccal cortical plate above (or below) the origin of the buccinator muscle attachment and spread posteriorly via the pterygoid venous plexus into the pterygopalatine and infratemporal fossa to reach the orbit via the inferior orbital fissure and the inferior ophthalmic vein or the facial vein and the superior ophthalmic vein. If the roots extend into the sinus, the infection enters the maxillary sinus and gives rise to maxillary sinusitis. The maxillary anterior teeth may produce orbital cellulitis by retrograde spread through the facial, angular, or ophthalmic veins, or by direct spread. ${ }^{56-60}$ Extensive communication between the facial and ophthalmic veins occurs at the medial canthal region above the medial palpebral ligament, where the angular vein anastomoses with the supratrochlear and supraorbital veins. ${ }^{59,60}$ The valveless nature of these veins allows extensive 2-way communication between the orbit, the face, nasal cavity, the sinuses, the pterygoid plexus of veins, and rapid uninterrupted spread of the infection. ${ }^{57,60}$ The superior and inferior ophthalmic veins have communication with the cavernous sinus; the former through the angular vein and the latter through the pterygoid venous plexus. ${ }^{57}$ The normal direction of venous flow is from the orbital veins to the cavernous sinus. ${ }^{59}$ Compartments where infection may localize are determined by the planes of fascia and the potential fascial spaces. ${ }^{58,60}$

The signs of orbital infection include swelling, chemosis, displacement of the globe, and decreasing visual acuity. ${ }^{55}$ A closed box anatomy of the orbit and surrounding structures predisposes these tissues to serious sequelae in orbital space abscesses that will affect the extraocular muscles, thus influencing extraocular eye movements. Significant abscesses may result in proptosis and (by elevated intraorbital pressure) congestion, compression, and constriction of the diameter or infarction of the optic nerve, the retina, and the choroids causing optic neuritis, optic atrophy, and blindness. ${ }^{55-60}$ If the infection continues to spread along the optic canal and optic nerve or the ophthalmic vein, superior orbital fissure syndrome, orbital apex syndrome, epidural and subdural empyema, meningitis, cerebritis, cavernous sinus thrombosis, brain abscess, and death may ensue. ${ }^{55,56,59}$ Clinically, the superior orbital fissure syndrome will be marked by the involvement of the third, fourth, fifth (ophthalmic division), and sixth cranial nerves and parasympathetic block. Thus, ophthalmoplegia, ptosis, proptosis, fixed eye, dilated pupil, and sensory interference along the ophthalmic division of the fifth 
cranial nerve (upper eyelid and forehead) will occur. ${ }^{61}$ Orbital apex syndrome includes the signs of superior orbital fissure syndrome and additionally optic neuropathy and blindness. ${ }^{61}$ The clinical manifestations of cavernous sinus involvement include marked eyelid edema; ophthalmoplegia from palsies of cranial nerves III, IV, and VI; paresthesia in the distribution of V1 and V2; bilateral orbital involvement; altered states of consciousness; and generalized sepsis. ${ }^{59,62}$ Elevated intraorbital pressure is the primary, and potentially reversible, mechanism of visual impairment produced by orbital cellulites. ${ }^{62}$ Forward displacement of the globe by the infection is limited by the extraocular muscles and the optic nerve. However, the blood supply to the nerve is also compromised by such traction. ${ }^{61}$ Furthermore, decreased vision may also occur as a result of septic optic neuritis and embolic or thrombotic lesions in the vascular supply of the optic nerve, the retina, or choroids. ${ }^{61}$ Therefore, damage to neurovascular, muscular, and soft tissues often results in permanent sequelae such as residual restricted eye movement, proptosis, diplopia, and loss of vision, as well as hemiparesis and seizures in more severe cases. $^{55,61}$

The following guidelines are to be followed for better management of the complications from local anesthesia. ${ }^{63}$

a. Reassure the patient regarding the usually transient nature of the complications.

b. Cover the affected eye with a gauze dressing to protect the cornea for the duration of anesthesia.

c. The patient should be escorted home by a responsible adult.

d. If ocular complications last longer than six hours, refer the patient to an ophthalmologist for evaluation.

Ocular complications from dental source can be prevented by observing following precautions

1. Injections into the vascular system must be avoided, aspiration prior to injection ${ }^{63}$

2. Slow injection are mandatory ${ }^{63}$

3. The knowledge of the surgical anatomy with regard to the particular nerve block ${ }^{63}$

4. Advise patients during dental patients not to hold their breath for a long time \& rather to take multiple breaths during the procedure to avoid retinal damage. ${ }^{30}$

5. Dental abscess or infection should be investigated for systemic immunocompromised condition prior to tooth extraction to avoid vision threatening complications or mortality. The dreadful complication of visual loss can be avoided if sinusitis is diagnosed and treated early \& appropriately. ${ }^{47}$

\section{CONCLUSION}

Assessing the immunocompromised status is very important for the management of dental patient to avoid fatal outcomes. The upper jaw forms the floor of the maxillary sinus and the upper teeth are continous with the whole midface and cranium, therefore while treating these teeth it is important for the practioner to consider the possibility of ocular complications. Furthermore while giving L.A proper techniques should be followed. When articaine is used in the dental clinics its increased diffusion through soft tissue and bone must be considered.

\section{REFERENCES}

1. Malden N, Kaye-Wilson LG, Hudson I, Valentine D. Transient uniocular blindness after dental extraction under general anesthetic. Br Dent J1993;231:667-668.

2. Krepler K, Wedrich A, Schranz R. Intraocular hemorrhage associated with dental implant surgery. Am J Ophthalmol1996;122:745-746.

3. Friberg TR. Retinal tear after teeth cleaning. JAMA 1995;273:1493.

4. Brodsky CD, Dower JS Jr. Middle ear problems after a GowGates injection. J Am Dent Assoc 2001; 132(10):1420-4.

5. Penarrocha-Diago M, Sanchis-Bielsa JM. Ophthalmologic complications after intraoral local anesthesia with articaine. Oral Surg Oral Med Oral Pathol Oral Radiol Endod 2000;90(1):21-4

6. Webber B, Orlansky H, Lipton C, Stevens M. Complications of an intra-arterial injection from an inferior alveolar nerve block. J Am Dent Assoc 2001;132(12):1702-4.

7. Cooper JC. Deviation of eye and transient blurring of vision after mandibular nerve anesthesia: report of a case. J Oral Surg Anesth Hosp Dent Serv 1962;20:151-2.

8. Rood J. Ocular complication of inferior dental nerve block. A case report. Br Dent J 1972;132(1):23-4.

9. De Keyzer K, Tassignon MJ. [Case report: acute unilateral loss of visual acuity after a visit to the dentist: an unusual complication after the use of an anesthetic combined with adrenaline.] Article in French. Rev Belge Med Dent 2004;59:30-3.

10. Rishiraj B, Epstein JB, Fine D, Nabi S, Wade NK. Permanent vision loss in one eye following administration of local anesthesia for a dental extraction. Int J Oral Maxillofac Surg 2005;34(2):220-3.

11. Tommazzoli-Gerosa L, Marchini G, Monaco A. Amaurosis and atrophy of the optic nerve: an unusual complication of mandibular-nerve anesthesia. Ann Ophthalmol 1988;20(5):170-1.

12. Wei Cheong Ngeow, Chen Kiong Shim,Wen Lin Chai. Transient Loss of Power of Accommodation in 1 Eye Following Inferior Alveolar Nerve Block: Report of 2 Cases. J Can Dent Assoc;72(10):727-31

13. Leopard PJ. Diplopia following injection of a local anaesthetic. Dent Pract Dent Rec 1971;22(3):92-4.

14. Goldenberg AS. Transient diplopia as a result of block injections. Mandibular and posterior superior alveolar. N Y State Dent J 1997;63(5):29-31.

15. Goldenberg AS. Transient dipoplia from a posterior alveolar injection.J Endod 1990;16(11):550-1.

16. Goldenberg AS. Diplopia resulting from a mandibular injection. JEndod 1983;9(6):261-2.

17. Marinho RO. Abducent nerve palsy following dental local 
analgesia.Br Dent J 1995;179(2):69-70.

18. Pickering T, Howden R. Gray's anatomy, descriptive and surgical.15th ed. London: Chancellor Press;1985. p. 703-9,805-30

19. Blaxter P, Britten MJ. Transient amaurosis after mandibular nerve block. Br Med J 1967; 1(5541):681.37

20. Pretterklieber ML, Skopakoff C, Mayr R. The human maxillary artery reinvestigated: I. Topographical relations in the infratemporal fossa. Acta Anat (Basel) 1991;142(4):281-7.

21. Roda RS, Blanton PL. The anatomy of local anesthesia. Quintessence Int 1994;25(1):27-38.

22. Singh S, Dass R. The central artery of the retina. I. Origin and course. Br J Ophthalmol 1960; 44:193-212.

23. Hyams SW. Oculomotor palsy following dental anesthesia. Arch Ophthalmol 1976;94(8):1281-2.

24. Bandres A, Penarocha M, Sanchis JM. [Complicaciones de la anestesia dental.] Anales Odontoestomatol 1997;3:87-95.

25. Aldrete JA, Narang R, Sada T, Tan Liem S, Miller GP.Reverse carotid flow - a possible explanation for some reactions to local anesthetic. J Am Dent Assoc 1977;94(6):1142-5.

26. Balaji S M. Transient diplopia in dental outpatient clinic: An uncommon iatrogenic event. Indian J Dent Res 2010;21:132-4

27. Hawkins JM, Isen D. Maxillary nerve block: The pterygopalitine canal approach. J Calif Dent Assoc 1998;26:658-64

28. Lee C. Ocular complications after inferior alveolar nerve block. The Hongkong Medical Diary 2006;11:4-5

29. Van Der Bijl P, Meyer D. Ocular complications of dental local anaesthesia. SADJ 1998;53:235-8.

30. Crean SJ, Powis A. Neurological complications of local anaesthetics in dentistry. Dent Update 1999;26:344-9.

31. Alexander Kiderman, Jawad A. A. Tair An eye for a tooth. Gerodontology 2013;30:83-84

32. Jones WL. Valsalva maneuver induced vitreous hemorrhage. J Am Optom Assoc 1995;66:301-304

33. Duane TD. Valsalva hemorrhagic retinopathy. Trans Am Ophthalmol Soc1972;70:298-313

34. Peñarrocha-Diago M, Sanchis-Bielsa JM. Ophthalmologic complications after intraoral local anesthesia with articaine Oral Surg Oral Med Oral Pathol Oral Radiol Endod. 2000 Jul;90(1):21-4

35. Campbell RL, Mercuri LG, Van Sickels J. Cervical sympathetic block following intraoral local anesthesia. Oral Surg Oral Med Oral Pathol 1979;47:223-6.

36. Carron H, Litwiller R. Stellate ganglion block. Anesth Analg 1975;54:567-70

37. Kronman JH, Kabani S. The neuronal basis for diplopia following local anesthetic injections. Oral Surg Oral Med Oral Pathol 1984;58:533-4.

38. Petrelli A, Steller RE. Medial rectus muscle palsy after dental anesthesia. Am J Ophtalmol 1980;90:422-4.

39. Marinho RM. Abducent nerve palsy following dental local analgesia. Br Dent J 1995; 179:69-70.

40. Lloyd E, Scher-DuBrul, editors. Anatomía oral. Barcelona: Doyma; 1990. p. 235-58.

41. Okeson JP, editor. Dolor orofacial según Bell. Barcelona: Quintessence; 1999.p.31-40.

42. Velayos JL, editor. Anatomía de la cabeza, con enfoque odontoestomatológico. 2nd ed. Madrid: Panamericana; 1998. p. $290-8$

43. Kelly R. Magliocca, Neil C. Kessel, and Gerald W. Cortright, Ann Arbor. Transient diplopia following maxillary local anesthetic injection. Oral Surg Oral Med Oral Pathol Oral
Radiol Endod 2006;101:730-3

44. Walker M, Drangsholt M, Czartoski TJ, Longstreth WT Jr. Dental diplopia with transient abducens palsy. Neurology 2004;63:2449-50.

45. Malamed S. Techniques of maxillary anesthesia. In: Reinhardt RW, Baxter S, Stericker GB, editors. Handbook of local anesthesia. St Louis, MO: Mosby; 1997. p. 164-8.

46. Sved AM, Wong JD, Donkor P, Horan J, Rix L, Curtin J, et al . Complications associated with maxillary nerve block anaesthesia via the greater palatine canal. Aust Dent J 1992;37:340-5.

47. Chun- kei Lee. Ocular complications after inferior alveolar nerve block. Dent Bull. 2006;11:4-5.

48. Subramaniam S, Tet CM, Wan Hitam WH, Hussein A, Khan SA, Pal HK, Embong Z. Orbital apex syndrome after tooth extraction in an immunocompromised patient. Int $\mathrm{J}$ Ophthalmol 2011;4(1):112-114

49. Zachariades N, Vairaktaris E, Mezitis M, Rallis G, Kokkinis C, Moschos M. Orbital abscess: visual loss following extraction of a tooth -- Case report. Oral Surg Oral Med Oral Pathol Oral Radiol Endod 2005;100(4):e70-e73

50. Kim IK, Kim JR, Jang KS, Moon YS, Park SW. Orbital abscess from an odontogenic infection. Oral Surg Oral Med Oral Pathol Oral Radiol Endod 2007;103(1):e1-e6

51. Edward FK. Orbital apex syndrome due to sinus infection. Laryngoscope 1974;84(3):353-371

52. Chee E, Looi A. Onodi sinusitis presenting with orbital apex syndrome. Orbit 2009;28(6):422-424

53. Mehra $\mathrm{P}$, Murad H. Maxillary sinus disease of odontogenic origin. Otolaryngeal Clin North A m 2004;37(2):347-364

54. El-Sayed Y, Al-Muhaimeid H. Acute visual loss in association with sinusitis.J Laryngeal Otol 1993;107(9):840-842

55. Hershey BL, Roth TC. Orbital infections. Semin Ultrasound CTMR 1997;18(6): 448-459

56. Miller EH, Kassebaum DK. Managing periorbital space abscess secondary to dentoalveolar abscess. A case report. JADA 1995; 126:469-72

57. Allan BP, Egbert MA, Myall RWT. Orbital abscess of odontogenic origin. Case report and review of the literature. J Oral Maxillofac Surg 1991;20:268-70.

58. Janakarajah N, Sukumaran K. Orbital cellulitis of dental origin: case report and review of the literature. $\mathrm{Br} \mathrm{J}$ Oral Maxillofac Surg 1985;23:140-5.

59. Gold RS, Silver L, Sager E. Pansinusitis, orbital cellulitis, and blindness as sequelae of delayed treatment of dental abscess. J Oral Surg 1974;32:40-3.

60. O'Ryan F, Diloreto D, Barber D, Bruckner R. Orbital infection: clinical and radiographic diagnosis and surgical treatment. J Oral Maxillofac Surg 1988;46:991-7.

61. Rosen D, Ardekian L, Abu El Naaj I, Fischer D, Peled M, Laufer D. Orbital infection arising from a primary tooth: a case report. Int J Ped Dent 2000;10:237-9.

62. Henry CH, Hughes CV, Larned DC. Odontogenic infection of the orbit. J Oral Maxillofac Surg 1992;50:172-8.

63. Zachariades N, Vairaktaris E, Mezitis M, Triantafyllou D, Papavassiliou D. Cerebral abscess and meningitis complicated by residual mandibular ankylosis. A study of the routes that spread the infection. J Oral Med 1986;41:14-20

Source of Support: Nil, Conflict of Interest: None Declared 